crystallography, which must at present, unfortunately, be regarded as a branch of mineralogy. And if they cannot acquire sound knowledge, how can they teach well? I feel quite sure that if the Science and Art Department would institute a summer course for teachers, where they would not have to waste their time over the merest rudiments, but could study practically the methods of crystal measurements, and the higher branches of mineralogical research, it would be largely taken advantage of by teachers and those who intend to become teachers. Failing this, I for one should be glad to hnow of any institution in this country or in Germany where such instruction could be obtained during the summer months.

G'asgow, December 3I, I 888 .

\section{Ventilating Bees.}

I Do not know whether it is generally known that here, and I believe in other tropical countries, there are in every hive what one can only describe as "ventilating bees." I mean that during the hot season two or three bees post themselves, on their heads, at the entrance of the hive, and fan the interior with the incessant motion of their wings. They are relieved at intervals by fresh bees, who carry on the process. They are kept to their duty by a sort of patrol of bees to insure their incessant activity. This is a well-authenticated and known fact, and as such may interest your readers.

Mauritius, November $2 \mathrm{r}$.

Eva M. A. Bewsher,

\section{Sonorous Sand at Botany Bay.}

REFERRING to the correspondence with regard to the so-called "musical sands," which has appeared in your columns, it may be of interest to record the fact that sand with similar properties is found in Botany Bay, New South Wales, not far from the spot where Captain Cook first landed. When displaced by pressure from above, or disturbed with the hand or stick, this sand emits a musical sound, which appears to vary in intensity according to the degree of moisture which it contains. Should any of your correspondents wish for specimens, I shall be happy to forward a small quantity to them.

Australian Museum, Sydney, November Í́, I 888.

\section{HOW RAIN IS FORMED.1}

$\mathrm{N}$ certain villages in the Indian Central Provinces, besides the village blacksmith, the village accountant, the village watchman, and the like, there is an official termed the gapogari, whose duty it is to make rain. So long as the seasons are good and the rain comes in due season, his office is no doubt a pleasant and lucrative one. It is not very laborious, and it is obviously the interest of all to keep him in good humour. But if, as sometimes happens, the hot dry weather of April and May is prolonged through June and July, and week after week the ryot sees his young sprouting crops withering beneath the pitiless hot winds, public feeling is wont to be roused against the peccant rain-maker, and he is led forth and periodically beaten until he mends his ways and brings down the much-needed showers.

You will hardly expect me, and I certainly cannot pretend, to impart to you the trade-secrets of the professional rain maker. Like some other branches of occult knowledge which Madam Blavatsky assures us are indigenous to India, this art of rain-making is perhaps not to be acquired by those who have been trained in European ideas; but we can at least watch and interrogate Nature, and learn something of her method of achieving the same end ; and if her scale of operations is too large for our successful imitation, we shall find that not only is there much in it that may well challenge our interest, but it may enable us to some extent to exercise prevision of its results.

Stated in the most general terms, Nature's process of rain-making is extremely simple. We have its analogue

${ }^{I}$ A Lecture delivered by H. F. Btanford, F.R.S., at the Hythe School of Musketry on November I, in the working of the common still. First, we have steam or water vapour produced by heating and evaporating the water in the boiler; then the transfer of this vapour to a cooler ; and finally we have it condensed by cooling, and reconverted into water. Heat is communicated to the water to convert it into vapour, and when that heat is withdrawn from it, the vapour returns to its original liquid state. Nature performs exactly the same process.

In the still, the water is heated until it boils; but this is not essential, for evaporation may take place at all temperatures, even from ice. A common little piece of apparatus, often to be seen in the window of the philosophical instrument maker, and known as Wollaston's cryophorus, is a still that works without any fire. It consists of a large glass tube with a bulb at each end, one of which is partly filled with water : and, all the air having been driven out of the tube by boiling the water, it is hermetically sealed and allowed to cool. It then contains nothing but water and water vapour, the greater part of which re-condenses when it cools. Now, when thus cold, if the empty bulb be surrounded by ice, or, better, a mixture of ice and salt, the water slowly distils over, and is condensed in the colder bulb, and this without any heat being applied to that which originally contained the water. And this shows us" that all that is necessary to distillation is that the condenser be kept cooler than the evaporater.

Nevertheless, at whatever temperature it evaporates, water requires heat, and a large quantity of heat, merely to convert it into vapour; and this is the case with the cryophorus; for if the evaporating bulb be wrapped round with flannel, and so protected from sources of heat around, the water cools down until it freezes. That is to say, it gives up its own heat to form vapour. A simple experiment that anyone may try with a common thermometer affords another illustration of the same fact. If a thermometer bulb be covered with a piece of muslin, and dipped into water that has been standing long enough to have the same temperature as the air, it gives the same reading in the water as in the air. But if when thus wetted it be lifted out and exposed to the air, it begins to sink at once, owing to the evaporation of the water from the wet surface, and it sinks the lower the faster it dries. In India, when a hot wind is blowing, the wet bulb sometimes sinks $40^{\circ}$ below the temperature of the air.

Now this is a very important fact in connection with the formation of rain, because it is owing to the fact that water vapour has absorbed a large quantity of heat - which is not sensible as heat, but must be taken away from it before it can be condensed and return to the liquid state-that vapour can be transported as such by the winds for thousands of miles, to be condensed as rain at some distant part of the earth's surface.

I have said that the quantity of absorbed heat is very large. It varies with the temperature of the water that is evaporating, and is the greater the lower that temperature. From water that is on the point of freezing it is such that one grain of water absorbs in evaporating as much heat as would raise nearly $5 \frac{1}{2}$ grains from the freezing to the boiling point. This is called the latent heat of water vapour. As I have said, it is quite insensible. The vapour is no warmer than the water that produced it, and this enormous quantity of heat has been employed simply in pulling the molecules of water asunder and setting them free in the form of vapour, which is merely water in the state of gas. All liquids absorb latent heat when they evaporate, but no other known liquid requires so much as water.

Many things familiar in every one's experience find their explanation in this absorption of latent heat. For instance, we feel colder with a wet skin than with a dry one, and wet clothes are a fruitful source of chills when the body is in repose; although, so long as it is in active exercise and producing a large amount of heat, since the evaporation 
only carries off the excess, no ill consequence may ensue. Again, if a kettle be filled with ice-cold water and put on a gas stove, suppose it takes ten minutes to bring it to boil. In that ten minutes the water has absorbed as much heat as raises it from $32^{\circ}$ to $2 \mathrm{I}^{\circ}$, an increase of $180^{\circ}$. Now, if it be left boiling, the gas-flame being kept up at the same intensity, we may assume that in every succeeding ten minutes the same quantity of heat is being absorbed by the water. But it gets no hotter: it gradually boils away. And it takes nearly an hour, or more than five times as long as it took to heat it, before the whole of the water has boiled away, since all this heat has been used up in converting it into steam. It was by an experiment of this kind that Dr. Black, in the last century, discovered the fact of latent heat, and determined its amount ; and it was the knowledge of this fact that led James Watt to his first great improvement in the steam-engine.

One more example I may give, which those who have been in India will be able to appreciate, and which those who intend to go there may some day find useful to know. Nothing is more grateful in hot dry weather than a drink of cold water. Now, ice is not always to be had, but when a hot wind is blowing, nothing is easier than to get cold water, if you have a pot or bottle of unglazed earthenware, such as are to be had in every bazaar, or, what is better, a leather water-bottle, called a chhagal, or a water-skin. All these allow the water to soak through and keep the outside wet; and if any one of them be filled with water and hung up in a hot wind, in the course of half an hour or an hour, the evaporation from the out side will have taken away so much heat that the contents may be cooled $20^{\circ}$ or $30^{\circ}$, notwithstanding that the thermometer may stand at $110^{\circ}$ or $115^{\circ}$ in the shade. Sodawater may be cooled in the same way if wrapped in straw and kept well wetted while exposed to the wind. But it is of little use to do as I have seen natives do sometimes, viz. put the bottles into a tub of water in a closed room. It is the evaporation that carries off the heat, otherwise the water is no cooler than the air around.

Now to return to our subject. The atmosphere always contains some vapour which the winds have taken up from the ocean, lakes, rivers, and even from the land, for there are but few regions so dry and devoid of vegetation that there is no moisture to evaporate. The quantity of water thus evaporated from large water surfaces is a question of some importance to engineers, who have to take account of the loss from reservoirs and irrigation tanks, and a good deal of attention has been given to measure the amount lost by evaporation. In England it has been found to vary in different years from 17 to 27 inches in the year, or say from $1 \frac{1}{2}$ to $2 \frac{1}{4}$ inches per month on an average. Now, since in the east of England the rainfall is only about 24 inches in the year, it follows that in that part of the Kingdom the loss by evaporation from a water surface is not very much less than the rain falling directly on the surface.

In dry countries the evaporation may exceed the local rainfall. In the tropics it has been found to average from $3 \frac{1}{3}$ to 6 inches per month in the dry season. In the case of a large tank at Nagpur, constructed to supply the city with water, it was found that the loss by evaporation, in the hottest and driest weather, was two and a half times as great as the quantity supplied for consumption.

These statistics will give some idea of the enormous evaporation that goes on from the water surfaces of the globe, and to this must be added all that takes place from the land. In the case of light showers, nearly the whole of the rain is re-evaporated; and probably, on an average, half of the total rainfall on the land is thus lost sooner or later, leaving not more than half for the supply of springs and rivers.

The quantity of vapour in the air is very variable. To us, in England, the west and south-west winds are the dampest, coming direct from the Atlantic, and north-east winds are the driest. The cause of their extreme dryn es I shall endeavour to explain presently. It is no doub partly due to the fact that they reach us from the land surface of Europe, but partly also to another cause to which I shall have to advert later on.

The quantity of vapour in the air is usually ascertained by the hygrometer, the ordinary form of which is a pair of thermometers, one having the bulb wet, the other dry, and observing the depression of the wet bulb. The principle of this I have already explained. But the same thing may be ascertained more directly by passing a measured quantity of air through a light apparatus containing sulphuric acid, or some other substance that absorbs water vapour greedily, and weighing the whole before and afterwards. The increase of the second weighment gives the weight of water absorbed. By such means it has been ascertained that air at $60^{\circ}$ can contain as much as $5 \frac{3}{4}$ grains of vapour in each cubic foot, and that air at $80^{\circ}$ can contain rather less than II grains in the same space. The quantity that air can hold increases therefore very rapidly with the temperature. But it is seldom that it contains this maximum amount, especially at the higher temperatures.

In order to condense any part of this vapour we must take away its latent heat. It is not sufficient merely to cool it till it reaches the temperature of condensation, but we have further to abstract $5 \frac{1}{2}$ times as much heat as would raise the condensed water from the freezing to the boiling point. Before, however, proceeding to consider how this cooling is effected, the question arises, What is the condensing point? For, obviously, since water can evaporate at all temperatures, so we should expect that it may condense at all temperatures. On what, then, does the condensing point depend?

I mentioned just now that air at the temperature of $60^{\circ}$ can contain as much as $5 \frac{3}{4}$ grains of vapour, and at $80^{\circ}$ rather less than II grains in each cubic foot. Obviously, then, if air at $80^{\circ}$, contaming this maximum quantity, be cooled to $6 c^{\prime \prime}$, it must get rid of more than 5 grains, or nearly half its vapour, and this excess must be condensed. I speak of air containing these quantities, but in point of fact it makes no appreciable difference whether air be present or not. An exhausted glass vessel of one cubic foot capacity can bold $5^{3}$ grains of vapour at $60^{\circ}$ and no more, and nearly II grains at $80^{\circ}$ and no more ; and if, when thus charged at $80^{\circ}$, its contents be cooled to $60^{\circ}$, inore than 5 grains will be condensed. If, however, it contain only $5 \frac{3}{4}$ grains at $80^{\circ}$, none will condense until the temperature falls to $60^{\circ}$, but any further cooling produces some condensation. Thus, then, the condensing point depends on the quantity of vapour present in the air, and is the temperature at which this quantity is the maximum possible for that temperature.

This preliminary point being explained, we may now proceed to inquire what means Nature employs to condense the vapour in the air, producing at one time dew and hoar-frost, at another time fog and cloud, and at another rain, hail, and snow.

Let us take the case of dew and hoar-frost first, as they are comparatively simple. And in connection therewith I may relate a little incident that took place at Calcutta some years ago. A gentleman, who had not much acquaintance with physical science, was sitting one evening with a glass of iced brandy and water before him. It was in the rainy season, when the air, though warm, is very damp, and he had a large lump of ice in his tumbler. On taking it up, he noticed to his surprise that the glass was wet on the outside, and was standing in quite a little pool of water on the table. At first he thought his tumbler was cracked, but putting his finger to his tongue he found the fluid tasteless. "Very odd!" he remarked ; "the water comes through the glass but the brandy doesn't."

Now, however with our present knowledge we may be inclined to smile at the simplicity of this remark, it so 
happens that up to the end of the last century very much the same explanation was popularly held to account for dew. It was supposed to be a kind of perspiration emitted from the earth, and no satisfac: ory explanation of the phenomenon had been arrived at by the physical philosopher's of the day. It remained for Dr. Wells to pr.ive, by a long series of observations and experiments, which have been quoted by Sir John Herschel and Mr. John Stewart Mill as a typical instance of philosophical inquiry, that the cold surface of grass and shrubs condenses the vapour previously held in suspension in the air. these surfaces being cooler than the air, and below its point of condensation. And such, of course, is also the case of the glass tumbler containing ice. Anyone may try the experiment for himsclf. To produce hoar-frost, it is only necessary to cool the condensing surface below the freezing point, which may be done by crushing some ice and mixing it with salt. A tin pot is better than a glass to make this experiment.

When not only the ground, but also the air to a considerable heiglit above it, is coo!ed in like minner, we have the production of fogg, for being the form in which the vapour is first conciensed, and consisting of water in drops too minute to be separately visible. The formation of fog is very much aided if the air be laden with smoke. Smoke consists of extremely minute particles of unburtit coal or other fuel, and these cool faster than the air at night, and so cool the air in contact with them. Fach one of them, too, condenses water on its surface, and being thus weighted they sink and form that dense for that Londoner's know so well.

Clouds are essentially the same as fog, but formed high up in the air. But in their case, and that of rain, snow, and hail, another and different cooling arency conces into play, and this will require some prehminary explanatiou.

I dare say that some of you may at some time or other have charged an air.gun. And if so, you will be aware that when so charged the reservoir becomes pret:y warm. Now this heat is produced, not, as might be supposed, by the friction of the piston in charging, but is due to the fact that work has been done upon the air by compressing it into a very small space; in other words, work has been converted into heat. If the compressed air be allowed to escape at once, its heat is re-converted into work. It has to make room for itself by thrusting aside the atmosphere into which it escapes, and when thus expanded it is no warmer than before it was compressed. Indeed, not so wat $m$, for it will already have parted with some of its heat to the metal chamber which contained it. And if when compressed it is allowed to cool down to the ordinary temperature, and then to escape, it will be cooled below that temperature just as much as it was heated by compression. Thus, if in being compressed it had been heated $100^{\circ}$, say from $60^{\circ}$ to $160^{\circ}$, and then allowad to cool to $60^{\circ}$, on escaping it will be cooled $100^{\circ}$ below $60^{\circ}$, or to $40^{\circ}$ Lelow zero, which is the temperature at which mercury freczes. This is the principle of the cold air chambers now so extensively employed on ship-board for the transport of frozen provisions from New Zealand and Australia.

Bearing in mind, then, this fact-that air in expanding and driving aside the air into which it expands is always cooled--let us see how this applies to the case before us, the production of cloud and rain.

The volume of a given weight of air -in other words, the space it occupies-depends on the pressure to which it is subject : the less this pressure the greater its volume. If we suppose the atmosphere divided into a numb.r of layers superimposed on each other, the bottom liver is clearly subject to the pressure of all those that rest on it. This is equal to about $14_{4}^{3}$ pounds on every square inch of surface. Another layer, say Icco feet above the ground, will clearly be under a less pressure, since Icco feet of air are below it ; and this 1000 feet of air weighs slightly less than half a pound for cvery square inch of horizontal surface. At 2000 fect the pressure will be less by nearly one pound per square inch, and sn on. If, then, any mass of air begins to ascend through the atmosphere, it will be continually subject to less and less pressure as it ascends; and therefore, as we have already seen, it expands, and becomes cooler by expansion. Cooling from this cause is termed dynamic cooling. Its rate may be accurately computed from the work it has to do in expanding.

It amnunts to I for every I $\&_{3}$ fect of ascent if the atir be dry or free from vapour, and if, as is alway's the case. it contains some vapour, the height will not be very much greater so long as there is no condensation. But so soon as this point is pastcd, and the vapour begins to condense as cloud, the latent heat set free retards the cooling, and the height through which this cloud-laden air must ascend to cool $1^{*}$ is considerably greater, and varies witl the temperature and pressure. When the barometer stands at 30 inches, and at the temperature of freezing, the air must rise 277 fect to lose 1 , and if the temperature is $60^{\circ}$ nearly too fect.

Comersely, dry air descending through the atmosphere and becoming denser as it descends, since it is continually hecoming subject to an increased pressure, is heated $i$ for every $1 \$_{3}$ feet of descent : and fogr and cloud-laden air at 30 inches of pressure and the freczing point will be warmed $1^{*}$ in 277 feet only, or if at $60^{-}$nearly 400 feet of descent, owing to the re-evaporation of the fog or cloud and the absorption of latent heat.

Now let us see how these facts explain the formation of cloud; and first I will take the case of the common cumulus or heap-cloud, which is the commonest cloud of the day-time in fine weather.

When after sunrise the air begins to be warmed, the lowest stratum of the atmosphere, which rests immediately on the ground, is warmed more rapidy than the higher strata. This is because the greater part of the sun's heat passes frecly through a clear atmosphere without warming it, and is absorbed i)y the ground, which gives it out again to the air immediately in contact with it. So sonn as the vertical decrease of temperature exceeds 1 in $I_{3}$ feet, the warm air betow besins to ascend, and the cooler air above to ciescend, and this interchange gradually extends higher and ligher, the ascending air being gradually cooled by expansion, and ceasing to rise when it has fallen to the same temperature as the air around it, This ascending air is more highly charged with vapour than that which descends to replace it, since. as was mentioned before, most land surfaces furnish a large amount of moisture, which evajorates when. they are licated by the sun. This process gocs on until some portion of the ascending air has become cooled to the point of condensation. No sooner does it attain this, than a small tuft of cumulus cloud appears on the top of the ascending current, and the movement which was invisible before row becomes visible. In a calm atmosphere each tiff of cloud has a flat base, which marks the height at which condensation tegins, but it is really only the top of an ascending column of air. No sooner is this cloud formed than the ascent becomes more rapid, because the cooling which checked its further ascent now takes place at a much slower rate, and therefore the cloud grows rapidly.

On a summer afternoon when the air is warm and very damp, such cumulus cloud ascends sometimes to very great heights, and c'cvelops into a thunder-cloud, condensing into ratin. Rain differs from fog and cloud only in the size of the water drops. In fog and cloud these are so minute that they remain suspended in the air. But as the cloud becomes denser, a number of them coalesce to form a rain-drop, which is large cnough to overcome the friction of the air. It then begins to fall, and having to traverse an enormous thickness of cloud below, it grows larger and larger by taking up more and more of the 
cloud corpuscules, so that when finally it falls below the cloud it may have a considerable size.

Such, then, is the mode in which rain is formed in an ordinary summer shower; and the more prolonged rainfall of stormy wet weather is the result of a similar process, viz. the ascent and dynamic cooling of the moist atmosphere. But in this case the movement is on a far larger scale, being shared by the whole mass of the atmosphere, it may be, over hundreds or thousands of square miles; and to understand this movement we shali have to travel somewhat further afield, and to inquire into the general circulation of the sreat atmospheric currents set in movement by the sun's action in the tropics, and modified by the earth's diurnal rotation and the distribution of the continents and oceans on its surface.

Before, however, entering on this subject, which will require some preliminary explanation, and in which we shall have to take account both of ascending and descending currents on a large scale, I will draw your attention to another and simpler case, in which both these classes of movements are prominently illustrated, and in which they exhibit their characteristic features in a very striking manner.

In the valleys of the Aips, more especially those to the north of the central chain, in Switzerland and the Tyrol, there blows from time to time a strong warm dry wind, krown as the Föhn. It blow; down the valleys from the central chain, melting the snows on its northern face, and although there is more or less clear sky overhead, all the southern slopes of the mountains are thickly clouded, and heavy rain falls on the lower spurs and the adjacent plain, replaced by snow at the higher levels up to the passes and the crest of the range. Cloudy weather also prevails to the north in Germany, and the weather is stormy over some part of Western Euro

It is only since the general introduction of telegraphic we.ther reports and the construction of daily weather charts have enabled us to take a general survey of the simultaneous movements of the atmosphere over the greater portion of Europe, that this Föhn wind has been satisfactorily explained. ${ }^{i}$ It is found that when a Föhn wind blows on the north of the Alps, the barometer is low somewhere to the north or north-west, in Germany, Northern France, or the British Isles, and high to the south-east, in the direction of Greece and the Eastern Mediterranean. Under these circumstances, since the winds always blow from a place of high barometer to one of low barometer, a strong southerly wind blows across the Alps. On their southern face it is forced to ascend, and therefore, as just explained, it is cooled and gives rain in L.ombardy and Venetia, and snow at higher elevations. But having reached the crest of the mountains, it descends to the northern valleys, and being by this time deprived of a large part of its vapour, it becomes warmed in its descent, owing to compression. absorbs and re-evaporates the cloud carried with it, and is then further warmed at the rate of $I^{\circ}$ for every 183 feet of descent. Thus it reaches the lower levels as a warm dry wind, its warmth being the effect of dynamic heating.

Other mountain chains afford examples of the same phenomenon. A very striking instance, which much im. pressed me at the time, is one that I witnessed many years ago in the mountains of Ceylon; and it was afterwards mentioned to me by Sir Samuel Baker, who had been equally struck by it. My own experience is as follows:- In June I86r, I paid a week's visit to the hill sanitarium of Newara Eliya, at an elevation of 6200 feet, on the western face of Pedro Talle Galle, the highest mountain in the island. The south-west monsoon was blowing steadily on this face of the range; and during the whole time of my stay it rained, as far as I am aware, without an hour's intermission, and a dense canopy of

I The explanation was originally given by Prof. J. Hann, of Vienna. cloud enveloped the hill face, and never lifted more than a few hundred feet above the little valley in which Newara Eliya is built. But on leaving the station by the eastern road that leads across the crest of the range to Badulla, at a distance of five miles one reaches the col or dip in the ridge near Hackgalle, and thence the road descends some 2000 feet to a lower table-land which stretches away many miles to the east. No sonner is this point passed than all rain ceases and cloud disapperrs, and one looks down on the rolling grassy hills bathed in the sunshine of a tropical sun, and swept by the dry westerly wind that descends from the mountain ridge. In little more than a mile one passes from day-long and week-long cloud and rain to constant sunshine and a cloudless sky.

As an almost invariable rule, or at least one with few exceptions, ascending air currents are those that form cloud and rain, and descending currents are dry and bring fine weather. And this holds good whatever may be the immediate cause of these movements. We may now proceed to consider these greater examples to which I have already referred.

In the great workshop of Nature, in so far at least as concerns our earth, with but few exceptions, all move. ment and all change, even the movements and energies of living things, proceed either directly or indirectly from the action of the sun. Nowhere is this action more direct and more strikingly manifested than in the movements of the atmosphere. Were the sun extinguished, and to become, as perhaps it may become long ages hence, a solid cold sphere, such as flyron imagined, "wandering darkling in eternal space," a few days would suffice to convert our mobile and ever-varying atmosphere into a stagnant pall, devoid of vapour, resting quiescent on a lifeless earth, held bound in a more than Arctic frost. From such a consummation, despite the supposed decaying energy of our sun, we may, however, entertain a reasonable hope that we are yet far distant.

Bearing in mind the all-embracing importance of the sun, let us see how the great movements of the at:mosphere are determined by the way in which the earth presents its surface to the solar rays.

Since the quantity of solar heat received on eacn part of the earth's surface depends on the directness or obliquity of his rays--in other words, on the height to which the sun ascends in the heavens at noon-being greatest where he is direc $t$ 'y overhead, as in summer in the tropics, it follows that the hottest zone of the earth is that in the immediate neighbourhood of the equator, and the coldest those around the poles.

Did time allow, and were the necessary appliances at hand, it would be easy to show you that both as a matter of experiment, and also as a deduction from physical laws, there must be under such circumstances a How of air from the colder to the warmer region in the lower atmosphere, and a return current above. And to a certain extent we have these constant winds prevailing for about $30^{\circ}$ on either side of the equator, in the trade-winds, which blow towards the equator in the lower atmosphere, and the anti-trades blowing in the opposite direction at a great height above the earth's surface.

In the neighbourhood of the equator there is a zone extending right round the earth in which the barometer is lower than either to the north or the south. It is due to the greater heat of the sun, and it is towards this that the trade winds blow. It shifts to some extent with the seasons, being more northerly in the summer of the northern hemisphere, and more southerly in that of the southern hemisphere; and its average position is rather to the north of the equator, owing to the fact that there is more land in the northern than in the southern hemisphere, and that land is more heated by the sun than the ocean.

This simple wind system of the trades and anti-trades does not extend right rounc' 'e earth, nor beyond $30^{\circ}$ or 
$40^{\circ}$ of latitude in either hemisphere. Were the earth's surface uniformly land or uniformly water, there probably would be a system of trade-winds all round the globe, blowing from both hemispheres towards the equator; but ever in that case they would not extend much, if at all, beyond their present limits. In the first place, every great mass of land sets up an independent system of air currents, since the land is hotter than the ocean in the summer, and colder in the winter. In the summer, therefore, there is a tendency to an indraught of air from the sea to the land in the lower atmosphere, and an outflow above, and in the winter the opposite; and this tendency modifies or interrupts the system of the trades and anti-trades. We have this tendency shown most distinctly in the monsonns of South-Eastern Asia, where, both in the India and China seas, a south-west wind in the summer takes the place which in the absence of the Asiatic continent would be held by a north-east tradewind. And it is only in the winter that a north-east wind blows, and this is then termed the north-east monsoon.

In the second place, as I have said, the system of trade-winds could not in any case extend far beyond their present limits in latitude, owing to the fact that the earth is a sphere and not a cylinder. Let us fix our attention for a moment on the anti-trades-- the upper winds which blow from the equator towards the poles. The equator, from which they start, is a circle about 24,900 miles in circumference; the poles are mere points, and, therefore, the whole of the air that blows towards the poles must turn back in any case before it reaches the pole, and must begin to turn back before it has gone very far on its journey. And, as a fact, a great part of it does turn back between $30^{\circ}$ and $40^{\circ}$ of latiturle, which I have already mentioned as being the limit of the trade-winds. A part of the remainder descends to the earth's surface, and sweeps the Northern Atlantic and the North Pacific as a south-west wind.

On the chart which represents the average distribution of atmospheric pressure in January, there are two somewhat interrupted zones of high pressure over the ocean in these latitudes. These mark the regions in which the anti-trades descend to the earth's surface, and from which the trade-winds start. Over the ocean in all higher latitudes, both in the northern and southern hemispheres, the barometer is low-for the most part, indeed, much lower than over the equator; and the region intervening between the zones of high pressure and the seat of lowest pressure is that of predominant south-west, or at all events westerly, winds. Since our islands are situated on the border of this region of low pressure, south-west are our prevailing winds.

But now two questions arise : first, Why are these winds westerly, and not simply south winds? and second, How is it that the barometer is so low over the North Atlantic and North Pacific Oceans, and also in the southern hemisphere in high latitucies, seeing that in these latitudes, at least in winter, the sun's heat is so much less than at the tropics? The chart represents the state of things in midwinter of the northern hemisphere, and yct everywhere to the north of latitude $40^{\circ}$ the deep blue tint indicates that the pressure is lower than even in the southern tropic, where the sun shines vertically overhead. Clearly this low pressure must be clue to sume other cause than the warmth of the air.

The explanation of this remarkable distribution of the atmospheric pressure, of the existence of two zones of high pressure in latitudes $30^{\circ}$ to $40^{\circ}$, and of very low pressure in higher latitudes, except in so far as they are modified by the alternations of land and water, was first given by the American physicist, Prof. Ferrel. Its full demonstration is to be obtained only from the consi- deration of somewhat recondite mechanical laws, but a general idea of the causes operating may be gathered from very simple considerations, which may be demonstrated with a terrestrial globe.

Starting with the well known fact that the earth revolves on its axis once in the twenty-four hours, let us see what will be the consequence, if we suppose a mass of any ponderable matter-that is, any substance having weight, no matter whether light or heavy - to be suddenly transferred from the equator to latitude $60^{\circ}$.

As the circumference of the earth at the equator is about 24,900 miles, any body whatever, apparently at rest at the equator, is carried round the earth's axis at the rate of 1036 miles an hour. But in latitude $60^{\circ}$, where the distance from the axis is only half as great as at the equator, it is carried round at only half the same rate, or 5 I 8 miles an hour; and at the pole it simply turns round on its own axis. Supposing, then, a mass of air to be suddenly transferred from the equator to latitude $60^{\circ}$, with the eastward movement that it had at the equator, it would be moving twice as fast to the east a; that part of the earth, and, to any person standing on the earth, would be blowing from the west with a force far exceeding that of a hurricane. It would be moving eastwards 5 I 8 miles an hour faster than the earth. Indeed, its movement would really be far greater than this. In virtue of a mechanical principle known as the law of the conservation of areas, which means that any body revolving round a central point, under the influence of a force that pulls it towards that point, describes equal areas in equal times, instead of only 518 miles, it would be revolving round the earth's axis 1554 miles an hour faster than that part of the earth. I need not, however, specially insist on this point, because, as a matter of fact, the air which constitutes the anti-trades is not suddenly transferred, but takes a day or two to perform its journey, and in the meantime by far the greater part of its eastward movement is lost by friction against the trade-wind which blows in the opposite direction underneath it. The point on which we have to fix our attention is that, when the anti-trades descend to earth, they still retain some of this eastward movement, and blow, not 'as south, but as south-west or west-south-west winds.

On the other hand, the trade-wind, which blows towards the equator, is coming from a latitude where the eastward movement is less than at the equator, and its own movement eastward is therefore less than that of the surface over which it blows. A person, therefore, standing on the earth, is carried eastward faster than the air is moving, and the wind seems to blow against him from the northeast. Similarly, to the south of the equator, the tradewind, instead of blowing from the south, comes from the south-east.

Thus, then, we have in both hemi:pheres a system of westerly winds in all higher latitudes than $40^{\circ}$, and a system of easterly winds-viz. the trade-winds-between about $30^{\circ}$ and the equator; and if the globe were either all land or all water, these systems would prevail right round the earth.

Now, it is the pressure of these winds, under the influence of centrifugal force, that causes the two zones of high barometer in latitudes $3 \mathrm{O}^{\circ}$ to $40^{\circ}$, and the very low pressure in higher latitudes. It is not difficult to understand how this comes about. You are probably aware that the earth is not an exact sphere, but what is termed an oblate spheroid-that is, it is slightly flattened at the poles and protuberant at the equator, the difference of the equatorial and polar diameters being about 26 miles. It has acquired this form in virtue of its rotation on its axis. If you whirl a stone in a sling, the stone has a tendency to fly off at a tangent, and, so long as it is retained in the sling. that tendency is resisted by the tension of the cord. In the same way, every object resting on 
the earth, and the substance of the earth itself, has a tendency to fly off at a tangent, in consequence of its rotation on its axis, and this tendency is resisted and overcome by gravity. Were the earth not revolving, its form, under the influence of gravity alone, would be a true sphere. If it were to revolve more rapidly than at present, it would be still more oblate, flatter at the poles, and more bulging in the tropical zone; if less rapidly, the flattening and bulging would be less.

This is precisely what happens with the west and east winds of which we have spoken. West winds are revolving faster than the earth, and tend to make the atmosphere more protuberant at the equator than the solid earth ; hence they press towards the equator, to the right of their path in the northern hemisphere, and this tendency increases rapidly in high latitudes. Easterly winds, on the other hand, tend to render the form of the atmosphere more nearly spherical, and they, too, press to the right of their path in the northern hemisphere or towards the pole. In the southern hemisphere, for the same reason, both press to the left. The result of these two pressures in opposite directions is to produce the two zones of high barometer in the latitudes in which we find them--viz. between the easterly trade-winds and the westerly winds, which are the anti-trades that have descended to the earth's surface. And the low barometer of higher latitudes is produced in like manner by the westerly winds pressing away from those regions.

Thus, then, we find that all this system of winds, and the resulting distribution of atmospheric pressure as indicated by the barometer, is the result of the sun's action in equatorial regions. It is this that gives the motive power to the whole system, so far as we have as yet traced it, and it is this that produces those great inequalities of atmospheric pressure that I have so far described.

It remains now to see how storms are generated by these westerly winds. In so far as they retain any southing, they are still moving towards the pole in the northern hemisphere - that is to say, they are advancing from all sides towards a mere point. Some portion of them must therefore be continually turning back as the circles of latitude become smaller and smaller. But they are now surface-winds, and in order so to return they must rise and flow back as an upper current. This they do by forming great eddies, or air-whirls, in the centre of which the barometer is very low, and over which the air ascends, and these great air-whirls are the storms of the temperate zone and of our latitudes. It is the ascent and dynamic cooling of the air in these great eddies that cause the prolonged rainfall of wet stormy weather. How the eddies originate, or, rather, what particular circumstance causes them to originate in one place rather than another, we can scarcely say, any more than we can say how each eddy originates in a rapidly-flowing deep river. Some very small inequality of pressure probably starts them, but, when once formed, they often last for many days, and travel some thousands of miles over the earth's surface.

Two such storms are represented on the charts of February $\mathrm{I}$ and 2, I883, one on the coast of Labrador, the other to the south-west of the British Isles. The first of these appears on the chart of January 28 , in the North Pacific, off the coast of British Columbia. Cn the 29 th it had crossed the Rocky Mountains, and was traversing the western part of the Hudson's Bay Territory. On the 3oth it had moved to the south-east, and lay just to the west of the Great Lakes, and on the 3Ist between Lake Superior and Hudson's Bay. On February I it had reached the position on the coast of Labrador shown in the chart, and on the 2nd had moved further to northeast, and lay across Davis's Straits, and over the west coast of Greenland. After this it again changed its course to south-east, and on February 4 passed to the north of Scotland, towards Denmark, and eventually on to Russia.

The second storm had originated off the east coast of the United States between January 28 and 29 , and on the following days crossed the Atlantic on a course somewhat to north of east, till, on February 2, it lay over England.

These storms always move in some easterly direction, generally between east and north-east, and often several follow in rapid succession on nearly the same track. It is this knowledge that renders it possible for the Meteorological Office to issue the daily forecasts that we see in the newspapers. Were it possible to obtain telegraphic reports from a few stations out in the North Atlantic, these storm warnings could be issued with much more certainty, and perhaps longer before the arrival of the storm than at present. In the case of such storms as that which reached our islands on February 2, we often have such warnings from America, but their tracks are often more to the north-east, in the direction of Iceland, in which case they are not felt on our coasts, and hence the frequent failure of these American warnings.

It is the region of low pressure in the North Atlantic that is the especial field of these storms. As they pass across it, they produce considerable modifications in the distribution of pressure, but some of its main features remain outstanding. Thus there is always a belt of high barometer between the storm region and the trade-winds, and in the winter there is almost always a region of high barometer over North America, and another over Europe and-Asia, however much they may shift their places, and be temporarily encroached on by the great storm eddies.

These regions of high pressure are the places where the winds descend, and, as I mentioned in the earlier part of this lecture, these winds are dry, and generally accompany fine weather. On the contrary, the eddies, where the air ascends, are damp and stormy, and especially that part of the eddy that is fed by the south-west winds that have swept the Atlantic since their descent, and so have become charged with vapour.

And now we are prepared to understand why east, and especially north-east winds are generally so dry. They are air that has descended in the area of high barometer that, especially in the winter and spring, lies over Europe and Asia, and has subsequently swept the cold landsurface, which does not furnish much vapour, and therefore they reach us as dry cold winds. To begin with, the air comes from a considerable height in the atmosphere, and in ascending to that height in some other part of the world, it must have got rid of most of its vapour in the way that has been already explained. In descending to the earth's level it must, of course, have been dynamically heated by the compression it has undergone, but all or nearly all this heat has been got rid of by radiation into free space on the cold plains and under the clear frosty skies of Northern Asia and Northern Europe, and it then blows outwards from this region of high barometer over the land, towards the warmer region of low barometer on the North Atlantic Ocean.

Thus we see that, in all cases, rain is produced by the cooling of the air, and that in nearly all, if not all, this cooling is produced by the expansion of the air in ascending from lower to higher levels in the atmosphere, by what is termed dynamic cooling. This last fact is not set forth so emphatically as it should be in some popular text-books on the subject, but it is an undoubted fact. It was originally suggested by Espy some forty years ago, but the truth is only now generally recognized, and it is one of the results which we owe to the great advance in physical science effected by Joule's discovery of the definite relation of equivalence between heat and mechanical work. 